DOI: $10.38136 /$ jgon.698866

\title{
Aile Planlaması Danışmanlık Hizmetinin Kadınların Kontraseptif Yöntem Tercihine Etkisi: Bir Tersiyer Merkez Deneyimi
}

\section{The Effect Of The Family Planning Counselling Service On Women's Choice Of Contraceptive Method: A Tertiary Healthcare Center Experience}

\author{
PInar $\mathrm{KIRICl}$ \\ Selçuk KAPLAN \\ Talip KARAÇOR \\ Mehmet Can NACAR
}

(1) Orcid ID:0000-0001-7616-4181

(1) Orcid ID:0000-0002-2887-6165

(1) Orcid ID:0000-0003-1349-1569

(1) Orcid ID:0000-0001-5463-4197

\section{${ }^{1}$ Adıyaman Üniversitesi Tıp Fakültesi,Kadın Hastalıkları ve Doğum}

\section{öz}

Amaç: Herkes, çocuk sahibi olup olmamaya veya ne zaman çocuk sahibi olacağına karar verme, etkin ve güvenilir aile planlaması (AP) yöntemlerine eşit olarak ulaşabilme ve AP hizmetleri açısından danışmanlık ve bilgilendirilme hakkına sahiptir. Bu çalışmanın amacı, kadınlara ait bazı özelliklerinin ve AP danışmanlık hizmetinin kadınların kontraseptif yöntem tercihine etkisini araştırmaktır.

Gereç ve Yöntemler: Kesitsel tipte gözlemsel araştırma tasarımına sahip bu çalışma, tersiyer bir merkezin Kadın Hastalıkları ve Doğum Kliniği Aile Planlaması Birimine başvuran 18-45 yaş arası sağlıkı gönüllü kadınlar ile yürütülmüştür. Kadınlara AP danışmanlık hizmetleri ve yöntem tercihlerine yönelik sorular içeren bir anket uygulanmıştır. Danışmanlık öncesi ve sonrası tercihleri karşılaşıııılmıştır.

Bulgular: Çalışmaya katılan 334 kadının ortanca gebelik sayısı ve ortanca yaşayan çocuk sayısı 3 olarak bulunmuşken, son doğumlarından bu yana ortanca 12 ay süre geçmiştir. Kadınların danışmanlık öncesi tercih etmeyi düşündükleri yöntemler arasında en sık bakırlı rahim içi araç (Cu-RIA), ikinci sırada kondom, üçüncü sırada kombine oral kontraseptif (KOK) yer alırken, danışmanlık sonrası kadınlar arasında Cu-RIA tercih sıklı̆ında artış, diğer yöntemlerin tercih sıklı̆ında ise azalış olmuştur. Kadınlar, AP danışmanlık hizmeti sonrası yöntem tercihini etkileyen en önemli faktör olarak yöntemin daha güvenli olduğunu düşünmeleri olduğunu bildirmiştir. Çalışmanın bir diğer önemli bulgusu, kadınların yaşayan çocuk sayısı arttıkça uzun süreli koruyuculuk sağlayan yöntemleri daha fazla sıkıkla tercih etmeleridir. Bununla birlikte, kadınların \%95,2'si AP danışmanlık hizmeti sunan personelin ilk önerdiği yöntemi tercih etmiştir.

Sonuç: AP danışmanlık hizmeti kadınların tercihlerine önemli düzeyde etki etmektedir. Bu hizmetlerin erişilebilir ve ulaşılabilir olması, kadınların kendi kişisel özellik ve sağık durumlarına uygun kontraseptif yöntem tercihini kolaylaştırabilecektir.

Anahtar Kelimeler: Aile planlaması danışmanlığı, kontraseptif yöntem, yöntem tercihi.

\section{ABSTRACT}

Aim: Everyone has the right to decide whether or not to have children, when to have children; to achieve effective and reliable family planning (FP) methods equally; and to receive FP counseling services. The aim of this study is to investigate the effects of women's characteristics and FP counseling service on women's choice of FP method.

Material and Methods: This cross-sectional observational study was conducted with 18-45 year aged healthy volunteers who admitted to the Family Planning Unit of the Gynecology and Obstetrics Clinic of a tertiary center. A questionnaire including questions about FP counseling services and method preferences was applied to women. Pre and post counseling preferences were compared.

Results: The median gravidity and the median number of living children of 334 women who participated in the study were both found 3 , while the median time has passed 12 months since their last birth. Among the methods that women consider to prefer before counseling, copper intrauterine device (IUD) was the most common, condom in the second place, combined oral contraceptive (POP) in the third place, while the frequency of choice of copper IUD increased and the frequency of choice of other methods decreased. Women reported that they thought the method was safer as the most important factor affecting method preference after FP counseling. Another important finding of the study is that, as the number of living children increases, women prefer methods that provide longterm protection more frequently. However, $95.2 \%$ of the women preferred the method recommended by the FP counselling staff.

Conclusion: FP counseling service has a significant impact on women's preferences. The availability and accessibility of these services will facilitate women's choice of contraceptive methods that are suitable for their characteristics and health status.

Keywords: Family planning counseling, contraceptive method, choice of method.an effective treatment option. 


\section{GíRiş}

Uluslararası Planlı Ebeveynlik Federasyonu'na göre dünyada yılda yarım milyonun üzerinde kadın gebelik ve doğuma bağlı nedenlerle ölmektedir[1]. AP danışmanlık hizmeti, bir kadının özelliklerine ve intiyaçlarına en uygun kontraseptif yöntemin seçmesini sağlayarak üreme sağlığını iyileştirir. AP danışmanlığı, üreme hizmetlerinin geliştirilmesinde, doğum kontrolü ile ilgili bilgilerin sağlanmasında ve doğurgan çağdaki kadınlar için uzun dönemli aile planlamasının desteklenmesinde kilit bir rol oynayarak anne, bebek ve çocuk ölümlerini önler ve sosyoekonomik kalkınmaya katkıda bulunur [2,3].

Karşılanmamış AP hizmetleri, medikal, sosyal ve sosyolojik olarak önemli bir sorun olabilecek istenmeyen gebeliklere neden olabilmektedir [4]. Dünya Sağlık Örgütü'ne göre yılda yaklaşık olarak 75 milyon istenmeyen gebelik oluşmakta ve bu gebelerin \%65'i ya herhangi bir AP yöntemi kullanmamakta ya da geleneksel bir yöntem kullanmaktadır [5]. Yılda ortalama 25 milyon güvensiz düşük gerçekleşmekte ve yaklaşık 47.000 kadın bu sebeple hayatını kaybetmektedir [5].

Türkiye'de Sağılk Bakanlığı tarafından ücretsiz olarak sunulan AP hizmetleri, 1965 yılında yürürlüğe giren 557 sayılı Nüfus Planlaması Hakkında Kanun ile desteklenerek; anne ve bebek sağıı̆ını iyileştirici sonuçlar yaratmıştır [6]. Türkiye Nüfus ve Sağlık Araştırması 2018 (TNSA 2018) sonuçlarına göre, Türkiye'de kadınların sadece $\% 49$ 'u modern bir AP yöntemi kullanıyorken, \%30'u herhangi bir yöntem kullanmamaktadır. TNSA 2018'in bir diğer çarpıcı bulgusu, kadınların \%12'sinde karşılanmamış AP hizmeti varlığıdır. Türkiye'de modern yöntem kullanımının nispeten düşük olması ve karşılanmamış AP hizmetlerinin yüksekliği kadın sağlığı açısından önemli bir sorun olarak görülmektedir[7].

AP danışmanlık hizmeti sırasında; eğitim ve danışmanlık veren personel, kontraseptif yöntem seçimi konusunda kişilere tavsiye sağlayabilir. Bununla birlikte, AP danışmanlık hizmeti sunan personele ait bilgi ve beceri eksiklikleri ve hizmeti alan kişilerle arasındaki yetersiz iletişim; yöntemlerin uygun kullanımı ve yönteme ait yan etkilerile ilgili önemli bilgilerin açıklanmasını zorlaştırabilir ve dolayısıyla yöntemin kullanımında kesilmeye neden olabilir [5 ]. Bu nedenle iyi yapılandırılmış AP danışmanlık hizmetleri, kadınların modern ve etkili yöntem kullanımını arttırarak, kadın ve çocuk sağlığını koruyucu ve geliştirici etkiler yaratır.

Tüm bu bilgiler ışığında, bu çalışmanın amacı, tersiyer bir merkezin AP birimine başvuran sağlıklı ve gönüllü kadınlara sunulan AP danışmanlık hizmetinin kadınların kontraseptif yöntem tercihine etkisini araştırmaktır.

\section{GEREÇ VE YÖNTEMLER}

Bu çalışma Temmuz 2018-Ocak 2019 tarihleri arasında Adıyaman Üniversitesi Tıp Fakültesi Kadın Hastalıkları ve Doğum Kliniği Aile Planlaması Birimine başvuran 356 hastanın verileri kullanılarak yapılan kesitsel bir çalışmadır. AP birimine 356 kadın başvurmuştur. Kadınların tümü çalışmaya katıım açııından değerlendirilmiştir.

Çalışma Adıyaman Üniversitesi Girişimsel Olmayan Araştırmalar Etik Kurulu tarafından onaylanmıştır (22.05.2018 tarihli ve 2018/4-15 sayılı). Çalışmaya katılmaya aday tüm katıımcılar sözel olarak bilgilendirilmiş ve bireysel onamları alınmıştır. Çalışma; İyi Klinik Uygulamalar Standartlarına uygun şekilde yürütülmüş ve makale yazımında Strengthening the Reporting of Observational studies in Epidemiology (STROBE) kontrol listesi kullanılmıştır [9].

\section{Çalışma popülasyonu}

Çalışma öncesinde GPower yazııımı kullanılarak, minimum örneklem büyüklüğü hesaplanmış; 0,2 etki büyüklüğü, 0,05 tip 1 hata, 0,95 güç ve 1 serbestlik derecesi için $n=325$ olarak bulunmuştur.
Temmuz 2018-Ocak 2019 tarihleri arasında AP birimine başvuran 334 sayıda hasta çalışmaya katımaları için değerlendirilmiştir. Çalışmaya dâhil edilme kriterleri 18-45 yaş arası olmak ve kontraseptif yöntem kullanmak için AP birimine başvurmuş olmaktır.

18 yaşın altında olmak, Türkçe konuşma ve yazma konusunda eksikliği bulunmak, başvuru öncesi kullanmak istediği yöntemi kendisi belirleyerek başvurmuş olmak ve çalışma için yazılı onam vermemiş olmak çalışma için dışlanma kriterleridir.

\section{Veri kaynağı ve çalışmanın değişkenleri}

Veriler çalışmaya katılmayı kabul eden katıımcılara yüz yüze görüşme tekniği ile uygulanan anket ile toplanmıştır. Ankette, sosyodemografik özellikler (yaş, boy, vücut ağırı̆̆ı, medeni durum, öğrenim durumu ve hane halkı aylık geliri), obstetrik özellikler (gravida, parite, abortus), ve AP yöntemine ilişkin sorulara yer verilmiştir.

Boy ve vücut ağırığı kullanılarak beden kitle indeksi (BKi) hesaplanmıştır. BKI $18,5 \mathrm{~kg} / \mathrm{m} 2$ 'nin altında ise zayıf, $18,5-24,9 \mathrm{~kg} / \mathrm{m} 2$ arasında ise normal kilolu, $25-29,9 \mathrm{~kg} / \mathrm{m} 2$ arasında ise fazla kilolu, $30 \mathrm{~kg} / \mathrm{m} 2$ ve üzerinde ise obez olarak sınıflandırımıştır.

Danışmanlık hizmeti AP yöntemleri ve danışmanlığı sertifikasına sahip ve tarafsız bir ebe tarafından AP danışmanlık yönergelerine uygun şekilde verilmiş, kesin bir karara varılamadığı durumlarda birim sorumlusu olan tarafsız bir kadın hastalıkları ve doğum uzmanına danışıımıştır.

\section{İstatistik analiz}

Veriler SPSS 23 istatistik yazılımı (IBM Corp. in Armonk, NY) kullanılarak analiz edilmiştir. Normal dağııma uymayan sayısal değişkenlerin tanımlayıcı istatistikleri ortanca ve minimum-maksimum değerler, kategorik değişkenlerin ise frekans (n) ve yüzde (\%) ile gösterilmiştir. Sayısal değişkenlerin dağııı ı Kolmogorov-Smirnov testi kullanılarak değerlendirilmiştir. Danışmanlık öncesi ve sonrası yöntem tercihlerinin karşılaştırılmasında ise Pearson Ki-kare testi ve Fisher's Exact Test kullanılmıştır. İstatistiksel anlamlıık sınıı (p) 0,05 olarak kabul edilmiştir.

\section{BULGULAR}

Kadınların 16'sı dahil edilme kriterlerini karşılamadığı için, 4'ü ise onam vermediği için çalışmaya dahil edilmemiştir. Çalışmaya katılmayı kabul eden uygun kadınlardan 2'si anketi yarıda bırakmıştır. Bu iki kadına sözel olarak sorulduğunda, her iki kadın da yarıda bırakma sebebi olarak o an yeterli süresinin olmadığını bildirmişstir (Şekil 1).

Şekil 1. Çalışmanın akış şeması
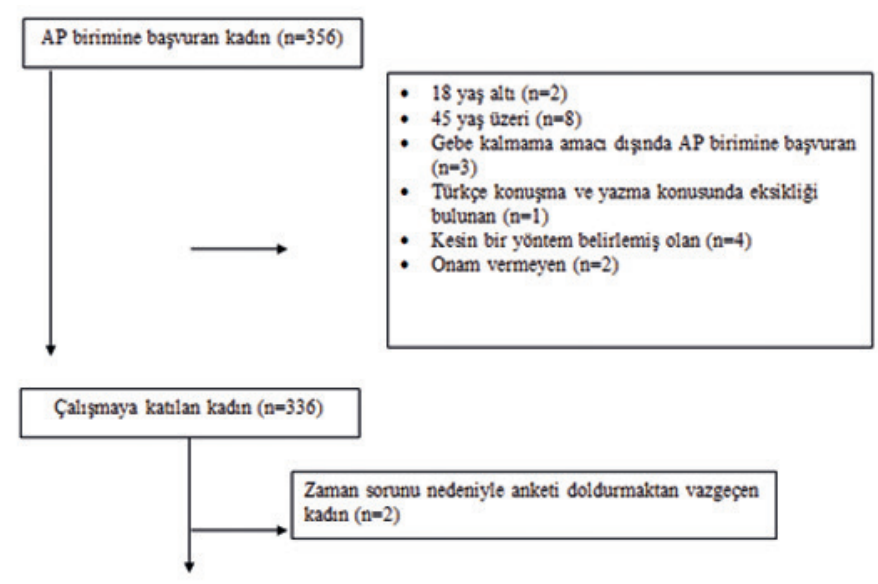

Analize dâhil edilen kadın (n-334) 
427 KIRICI P. ve ark.

Katılımcı kadınların ortanca yaşı 31,5 yıl iken en düşük 18 en yüksek ise 43 olarak saptanmıştır. BKi sınıflamasına göre kadınların 4'ü $(\% 1,2)$ zayıf, $115^{\prime} \mathrm{i}$ $(\% 34,4)$ normal kilolu, 153 'ü $(\% 45,8)$ fazla kilolu ve 62 'si ise $(\% 18,6)$ obezdir. Kadınların hepsi evli iken, 90' (\%26,9) ilkokul mezunu, 85'i (\%25,4) ortaokul mezunu, 92'si $(\% 27,6)$ lise mezunu ve 67'si $(\% 20,1)$ üniversite ve üzeri öğrenim düzeyine sahiptir. Kadınların 20'si (\%6,0) 1000 TL hane halkı gelirine sahip iken, \%44,6'sı1000-2000 TL arası, yaklaşık yarısı ise 2000TL ve üzeri hane halkı gelirine sahiptir (Tablo 1).

Tablo 1. Katılımcıların sosyodemografik özellikleri

\begin{tabular}{|c|l|}
\hline Özellik (n=334) & \\
\hline Yaş (yı1), Ortanca (minimum-maksimum) & $31,5(18,0-43,0)$ \\
\hline Beden kitle indeksi, $\mathrm{n}(\%)$ & \\
\hline Zayıf & $4(1,2)$ \\
\hline Normal kilolu & $115(34,4)$ \\
\hline Fazla kilolu & $153(45,8)$ \\
\hline Obez & $62(18,6)$ \\
\hline Medeni durum, n (\%) & \\
\hline Bekâr & $0(0,0)$ \\
\hline Evli & $334(100,0)$ \\
\hline Öğrenim durumu, n (\%) & \\
\hline İlkokul mezunu & $90(26,9)$ \\
\hline Ortaokul mezunu & $85(25,4)$ \\
\hline Lise mezunu & $92(27,6)$ \\
\hline Üniversite mezunu & $61(18,3)$ \\
\hline Yüksek lisans ve üzeri & $6(1,8)$ \\
\hline Hane halk1 aylık geliri, n (\%) & \\
\hline 1000 TL altı & $20(6,0)$ \\
\hline $1000-2000$ TL arası & $149(44,6)$ \\
\hline $2000-3000$ TL arası & $68(20,4)$ \\
\hline $3000-4000$ TL arası & $53(15,9)$ \\
\hline 4000 TL üzeri & $44(13,2)$ \\
\hline
\end{tabular}

n: Hasta sayıIs, TL: Türk Lirası

Kadınların ortanca gebelik sayısı 3, ortanca canlı doğum sayısı 3, ortanca düşük sayısı 0 , ortanca küretaj sayısı 0 ve ortanca yaşayan çocuk sayısı 3 olarak bulunmuştur. Kadınların 213 'ünün $(\% 63,8)$ son doğumu vajinal yolla, 121 'inin ise $(\% 36,2)$ sezaryen ile gerçekleşmiştir. Kadınların son doğumlarından bu yana ortanca 12,0 ay süre geçmiştir (Tablo 2).

Tablo 2. Katılımcıların obstetrik özellikleri

\begin{tabular}{|l|l|}
\hline Özellik (n=334) & \\
\hline Gebelik sayısı, Ortanca (minimum-maksimum) & $3,0(1,0-9,0)$ \\
\hline Canlı doğum sayıs1, Ortanca (minimum-maksimum) & $3,0(1,0-8,0)$ \\
\hline Düşük sayısı, Ortanca (minimum-maksimum) & $0,0(0,0-1,0)$ \\
\hline Küretaj sayıs1, Ortanca (minimum-maksimum) & $0,0(0,0-4,0)$ \\
\hline Yaşayan çocuk sayısı, Ortanca (minimum-maksimum) & $3,0(1,0-8,0)$ \\
\hline Son doğum şekli, n (\%) & \\
\hline \multicolumn{1}{|c|}{ Vajinal } & $213(63,8)$ \\
\hline \multicolumn{1}{|c|}{ Sezaryen } & $121(36,2)$ \\
\hline $\begin{array}{l}\text { Son doğumdan sonra geçen zaman (ay), Ortanca (mini- } \\
\text { mum-maksimum) }\end{array}$ & $12,0(1,0-$ \\
\hline
\end{tabular}

n: Hasta Sayısı

Kadınların danışmanlık öncesi tercih etmeyi düşündükleri ve danışmanlık sonrası tercih ettikleri yöntemlerin karşılaştırması Tablo 3'te sunulmuştur. Buna göre, 120 kadın $(\% 35,9)$ danışmanlık öncesi bakırlı rahim içi araç (Cu-RIA) tercih etmeyi düşünürken, danışmanlık sonrası 302 kadın $(\% 90,4)$ Cu-RIA'yı tercih etmiştir. Aradaki bu fark istatistiksel olarak anlamlı bulunmuş- tur $(p<0,001)$. Bunun dışında, danışmanlık öncesi diğer AP yöntemlerini tercih etmeyi düşünen kadınların danışmanlık sonrası tercihini değiştirmesi istatiksel olarak anlamlıdır. Geri çekme yöntemini tercih etmeyi düşünen 3 kadın, danışmanlık sonrası diğer yöntemleri tercih etmiş, ancak bu fark istatistiksel olarak anlamlı bulunmamıştır ( $p=0,249$ ) (Tablo 3).

Tablo 3. Katılımcıların danışmanlık öncesi ve danışmanlık sonrası yöntem tercihleri

\begin{tabular}{|l|l|l|l|}
\hline $\begin{array}{l}\text { Yöntem tercihi } \\
(\mathbf{n}=\mathbf{3 3 4})\end{array}$ & $\begin{array}{l}\text { Danışmanlık } \\
\text { öncesi, } \mathbf{n}(\%)\end{array}$ & $\begin{array}{l}\text { Danışmanlık son- } \\
\text { rası, n (\%) }\end{array}$ & p \\
\hline Bakırlı RİA & $120(35,9)$ & $302(90,4)$ & $<0,001^{*}$ \\
\hline Hormonlu Rं̇A & $8(2,4)$ & $1(0,3)$ & $0,038^{* *}$ \\
\hline KOK & $58(17,4)$ & $16(4,8)$ & $<0,001^{*}$ \\
\hline Kondom & $67(20,1)$ & $8(2,4)$ & $<0,001^{*}$ \\
\hline BTL & $31(9,3)$ & $3(0,9)$ & $<0,001^{*}$ \\
\hline Deri altı implant & $20(6,0)$ & $4(1,2)$ & $<0,001^{*}$ \\
\hline DMA & $27(8,1)$ & $0(0,0)$ & $<0,001^{*}$ \\
\hline Geri çekme & $3(0,9)$ & $0(0,0)$ & $0,249^{* *}$ \\
\hline
\end{tabular}

RiA: Rahim içi araç, KOK: Kombine oral kontraseptif, BTL: Bilateral tubal ligasyon, DMA: Depo Medroksiprogesteron Asetat.

* Pearson Ki-kare testi kullanılmıştır.

** Fisher's Exact Test kullanılmıştır.

Kadınların 269'u (\%80,5)'i, danışmanlık sonrası yöntem tercihini etkileyen en önemli faktörün yöntemin daha güvenilir olması olduğunu, 38'i $(\% 11,4)$ kolay uyum sağlayabileceği bir yöntem olması olduğunu ve 27 'si $(\% 8,1)$ ise kısa süreli bir yöntem olması olduğu belirtmiştir (Tablo 4).

Tablo 4. Katılımcıların danışmanlık sonrası tercihlerinin en önemli sebepleri

\begin{tabular}{|l|l|}
\hline En önemli tercih sebebi (n=334) & $\mathbf{n}(\mathbf{\%})$ \\
\hline Daha güvenli olduğunu düşünme & $269(80,5)$ \\
\hline Daha kolay uyum sağlama & $38(11,4)$ \\
\hline Kısa süreli koruma sağlaması & $27(8,1)$ \\
\hline
\end{tabular}

n: Hasta Sayısı

Bir yaşayan çocuğa sahip olan 36 kadının 9'u $(\% 25,0)$ kısa süreli, 27 'si $(\% 75,0)$ uzun süreli; iki çocuğa sahip olan 95'inin 6'sı $(\% 6,3)$ kısa süreli, 89'u $(\% 93,7)$ uzun süreli; üç ve üzeri yaşayan çocuğa sahip olan 203 kadının ise 9'u $(\% 4,4)$ kısa süreli, 194'ü $(\% 95,6)$ uzun süreli koruma sağlayan AP yöntemi tercih etmiştir. Dağılımlar arasındaki bu fark istatistiksel olarak anlamlı bulunmuştur $(p<0,001)$ (Tablo 5).

Tablo 5. Katılımcıların yaşayan çocuk sayılarına göre danışmanlık sonrası yöntem tercihlerinin dağılımı

\begin{tabular}{|c|c|c|c|c|c|c|c|c|}
\hline & \multicolumn{5}{|c|}{ Yöntem Tercihi } & \multirow{2}{*}{\multicolumn{2}{|c|}{ Toplam }} & \multirow[t]{3}{*}{$p$} \\
\hline & \multicolumn{2}{|c|}{$\begin{array}{l}\text { Kısa süreli } \\
\text { koruma sağ- } \\
\text { layan }\end{array}$} & \multicolumn{2}{|c|}{$\begin{array}{l}\text { Uzun süreli ko- } \\
\text { ruma sağlayan }\end{array}$} & \multirow[b]{2}{*}{$\mathrm{n}$} & & & \\
\hline & $\mathrm{n}$ & $\%$ & $\mathrm{n}$ & $\%$ & & $\%$ & & \\
\hline \multirow{3}{*}{$\begin{array}{l}\text { Yaşayan } \\
\text { çocuk } \\
\text { sayısı }\end{array}$} & 1 & 9 & 25,0 & 27 & 75,0 & 36 & 100,0 & $<0,001 *$ \\
\hline & 2 & 6 & 6,3 & 89 & 93,7 & 95 & 100,0 & \\
\hline & $\begin{array}{l}3 \text { ve } \\
\text { üzeri }\end{array}$ & 9 & 4,4 & 194 & 95,6 & 203 & 100,0 & \\
\hline \multicolumn{2}{|l|}{ Toplam } & 24 & 7,2 & 310 & 92,8 & 334 & 100,0 & \\
\hline
\end{tabular}

${ }^{*}$ Pearson Ki-kare testi kullanılmıştır.

AP danışmanlık hizmeti sunan personelin ilk olarak Cu-RIA önerdiği 299 kadının 293'ü $(\% 98,0)$ Cu-RíA tercih etmişken, diğerleri daha farklı bir yöntem tercih etmişlerdir. Danışman personel kimseye hormonlu (levoneorgesterollü) RIA önermemişken, kombine oral kontraseptif (KOK) önerdiklerinin yaklaşık üçte ikisi KOK, kalanı ise Cu-RIA tercih etmiştir. AP danışmanlık personelinin kondom kullanımı önerdiği 8 kadından 7'si $(\% 87,5)$ kondom tercih etmişken, 
bilateral tubal ligasyon (BTL) önerdiği bir BTL tercih etmiştir. Danışman, 4 kadına deri altı implant önermişken, bu kadınların 3'ü bu öneriye uygun tercih yapmış, biri iseCu-RiA'yı tercih etmiştir. Sonuç olarak, 334 kadının 318'i (\%95,2) AP danışmanının ilk olarak önerdiği yöntemi tercih etmiştir (Tablo 6)

Tablo 6. Danışmanlık hizmeti sunan personelin ilk önerdiği yönteme göre katılımcıların tercih ettikleri yöntem dağılımı.

\begin{tabular}{|c|c|c|c|c|c|c|c|c|c|c|c|c|c|c|c|}
\hline & & \multicolumn{12}{|c|}{ Katılımcıların tercih ettikleri yöntem } & \multirow{2}{*}{\multicolumn{2}{|c|}{ Toplam }} \\
\hline & \multicolumn{2}{|c|}{ Bakırlı RİA } & \multicolumn{2}{|c|}{$\begin{array}{c}\text { Hormonlu } \\
\text { RİA }\end{array}$} & \multicolumn{2}{|c|}{ KOK } & \multicolumn{2}{|c|}{ Kondom } & \multicolumn{2}{|c|}{ BTL } & \multicolumn{2}{|c|}{$\begin{array}{l}\text { Deri altı } \\
\text { implant }\end{array}$} & \multirow[b]{2}{*}{$\mathbf{n}$} & & \\
\hline & $\mathbf{n}$ & $\%$ & $\mathbf{n}$ & $\%$ & $\mathbf{n}$ & $\%$ & $\mathbf{n}$ & $\%$ & $\mathbf{n}$ & $\%$ & $\mathbf{n}$ & $\%$ & & $\%$ & \\
\hline \multirow{6}{*}{$\begin{array}{l}\text { Danışmanlık } \\
\text { hizmeti sunan } \\
\text { personelin ilk } \\
\text { önerdiği yöntem }\end{array}$} & $\begin{array}{l}\text { Bakırlı } \\
\text { RİA }\end{array}$ & 293 & 98,0 & 0 & 0,0 & 2 & 0,7 & 1 & 0,3 & 2 & 0,7 & 1 & 0,3 & 299 & 100,0 \\
\hline & $\begin{array}{l}\text { Hormonlu } \\
\text { RİA }\end{array}$ & 0 & 0,0 & $\mathbf{0}$ & $\mathbf{0 , 0}$ & 0 & 0,0 & 0 & 0,0 & 0 & 0,0 & 0 & 0,0 & 0 & 0,00 \\
\hline & KOK & 8 & 36,4 & 0 & 0,0 & 14 & 63,6 & 0 & 0,0 & 0 & 0,0 & 0 & 0,0 & 22 & 100,0 \\
\hline & Kondom & 0 & 0,0 & 1 & 12,5 & 0 & 0,0 & 7 & 87,5 & 0 & 0,0 & 0 & 0,0 & 8 & 100,0 \\
\hline & BTL & 0 & 0,0 & 0 & 0,0 & 0 & 0,0 & 0 & 0,0 & 1 & 100,0 & 0 & 0,0 & 1 & 100,0 \\
\hline & $\begin{array}{l}\text { Deri altı } \\
\text { implant }\end{array}$ & 1 & 25,0 & 0 & 0,0 & 0 & 0,0 & 0 & 0,0 & 0 & 0,0 & 3 & 75,0 & 4 & 100,0 \\
\hline \multicolumn{2}{|l|}{ Toplam } & 302 & 90,4 & 1 & 0,3 & 16 & 4,8 & 8 & 2,4 & 3 & 0,9 & 4 & 1,2 & 334 & 100,0 \\
\hline
\end{tabular}

RIA: Rahim içi araç, KOK: Kombine oral kontraseptif, BTL: Bilateral tubal ligasyon, n: Hasta Sayısı

\section{TARTIŞMA}

Bu çalışmada bir üniversite hastanesi kadın hastalıkları ve doğum bölümü altında hizmet sunan aile planlaması birimine başvuran kadınların kontraseptif yöntem tercihlerini etkileyen faktörleri araştııımıştır. Kadınların danışmanlık öncesi tercih etmeyi düşündükleri yöntemler arasında en sık Cu-RİA kullanımı, ikinci sırada kondom kullanımı, üçüncü sırada KOK kullanımı yer almaktaydı. Danışmanlık sonrası bu sıklık sıralaması pek değişmemiştir. Ancak danışmanlık sonrası kadınlar arasında Cu-RİA tercih sıklığında artış, diğer yöntemlerin tercih sıklı̆ında ise azalma olmuştur. Kadınlar, AP danışmanlık hizmeti sonrası yöntem tercihini etkileyen en önemli faktör olarak yöntemin daha güvenli olduğunu düşünmeleri olduğunu bildirmiştir. Çalışmanın bir diğer önemli bulgusu, kadınların yaşayan çocuk sayısı arttıkça, bakırlı RIA, BTL, deri altı implant gibi uzun süreli koruyuculuk sağlayan yöntemleri daha fazla sıklıkla tercih etmeleridir. Bununla birlikte, kadınların \%95,2'si AP danışmanlık hizmeti sunan personelin ilk önerdiği yöntemi tercih etmişsir.

Uzun süreli koruyucu etkiye sahip yöntemler istenmeyen gebeliklerin büyük çoğunluğunu önleyebilmektedir. Düşük ve orta gelirli ülkelerde istenmeyen gebeliği olan kadınların kullandıkları yöntemler incelendiğinde kadınların \%30'unun kısa süreli, \%5'inde ise uzun süreli koruyuculuk sağlayan yöntemlerin kullanıldığı görülmüştür [5]. Bir başka çalışmada kontraseptif yöntem kullanımında artışa rağmen istenmeyen gebeliklerin tüm gebeliklerin \%30'unu oluşturduğu belirtilmiş olup, uzun süreli AP yöntemleri olan $\mathrm{Cu}$ RIA, levonorgesterollü RIA ve implante kontraseptiflerin etkili ve güvenli seçenekler olduğu vurgulanmıştır [10]. Dahası aynı çalışmada bu yöntemlerin yeterince kullanılmadığı dünya çapında yaklaşık \%15,5'inde intrauterin yöntemlerin ve sadece \%3,4'ünde implante kontraseptif yöntemlerin kullanıldığı bildirilmiştir. Oysaki bu uzun etkili geri dönüşümlü kontraseptif yöntemler; kısa yöntemlerden daha etkili, günlük kontrol yada koital uyum gerektirmeyen, ucuz ve olumsuz östrojen yan etkilerinden bağımsız yöntemlerdir [10]. AP danışmanlığı sırasında, yöntemlerin kullanım kolaylığı, etkililiği, güvenliği ve geri dönüşümlü olmaları hakkında bilgi verildiğinde, uzun etkili yöntemler, kadınlar tarafından sadece "uzun etkili" değil, aynı zamanda "kalıcl" olarak da kabul edilmektedir [11].

Benzer olarak başka bir çalışmada üreme çağındaki kadınların \%10'undan azında bu yöntemlerin kullanıldığı bildirilmiş, fakat uygun AP danışmanlığı ile bu oranın arttırılarak istenmeyen gebeliklerin önlenebileceği ve düşükleri azaltacağı vurgulanmıştır [12]. Bizim çalışmamızda bu çalışmalardan farklı olarak AP danışmanlık merkezine başvuran kadınlarda başvuru sırasında da uzun süreli kontraseptif yöntemlerin ön planda düşünülmesidir. AP danışmanlık hizmeti ile bu kadınlarda güvenli yöntemlerin seçim sıklığı artmıştı.

Düşük ve orta gelirli ülkelerde çeşitli sosyoekonomik ve kültürel faktörler nedeniyle yüksek düzeyde karşılanmamış AP intiyacı eşlerin istememesi, kadınların yan etki konusundaki çekinceleri ve sağlığa olumsuz etkilerine dair önyargılar gibi nedenlere bağlanmıştır. Bu ülkelerde kadının yaşı ve öğrenim düzeyi artııça karşılanmamış AP intiyacı azalmakta, çocuk sayısı arttıkça ise intiyaç artmaktadır [13]. Gana'da 5 kentsel aile planlaması kliniğine başvuran kadınlar arasında yapılan bir çalışmada, Pakistan'da bir üniversite hastanesinde yapılan bir çalışmada ve Hindistan'da doğurganlık çağındaki kadınlar üzerinde yapılan araştırmalarda; AP danışmanlık hizmeti ile yan etkilerin açıklanması ve yapılan öneriler sonucu tercihlerin değiştiği, doğurganlık arttıkça AP danışmalık hizmetinin arttığı ve uzun süreli, etkili kontraseptif yöntemlerin tercih edildiği bildirilmiştir [14-16]. Bizim çalışmamızda da doğurganlık arttıkça AP danışmanlık için başvuru oranının artıığı ve AP danışmalık hizmeti alan kadınların önerilen ilk yöntemi tercih ettiği görülmüştür. Yöntemlerin etkinliği ve yan etkileri konusunda kadınlara yeterli AP danışmanlık verilmesi, kadınların "uygun" yöntem tercihini kolaylaştırabilecektir.

Avusturya, Belçika, Çek Cumhuriyeti ve Slovakya, Hollanda, Polonya, İsveç, İsviçre, İsrail, Rusya ve Ukrayna'da doğum kontrol danışmanlığı öncesi ve sonrası kadınların kontraseptif seçeneklerini değerlendiren kesitsel bir çalışma olan CHOICE çalışmasında da benzer şekilde danışmanlığın kadınların tercihini etkilemede önemli bir etken olduğu sonucuna varılmıştır [17-19]. Bu bulguda bizim çalışmamızı desteklemektedir.

AP danışmanlık hizmetlerinin içeriğinin ve sunum türünün hizmeti alanlar tarafından kabulü, bu kişilerin sosyokültürel ve demografik özellikleri ile doğrudan ve yüksek düzeyde ilişkilidir [20-24]. Bir çalışmada sosyoekonomik düzeyi düşük kadınlarda yetersiz AP danışmanlık hizmetine bağlı olarak istenmeyen gebeliklerin artığı, AP danışmanlık hizmeti alan kadınlarda bu oranın azaldığı bildirilmiştir [25]. AP danışmanlığı sırasında, tüm bu etkenler göz önünde bulundurularak kadınlarla iletişim kurulması, kadınların yöntem tercihi kararlarını destekleyebilir ve tutarlı seçimler yapmalarına yardımcı olabilir [22]. Çalışmamıza katılan kadınların yüksek öğrenim düzeyine sahip olması AP danışmanlık hizmetindeki başarımızı ve çalışmada geleneksel yöntem kullanımının düşüklüğünü açıklayabilir.

Çalışmanın kısıtıııkları arasında en önemlisi, çalışmanın tek merkezli olmasıdır. Bir diğer önemli kısıtlıık ise, çalışma konusunun katıımcılar açısından nispeten özel olması nedeniyle verilen cevaplarda yanlılık olabilmesidir. 
Bunu test edebilmek için katılımcılara anketi doldururken hissettikleri rahatığı 1 ile 5 puan arasında değerlendirmesi istenmiş, sonuçlara göre yalnızca dört katıIımcı 3 puan, 41 katıımcı 4 puan ve 289 katılımcı ise 5 puan vermiştir. Bu sonuç, kadınların çoğunun anketi rahat bir şekilde doldurduğunu göstermiştir. Çalışmanın bir diğer kısıtılığı ise, kadınların kontraseptif yöntem tercihine etkili olabilecek, eşlerin yöntem tercihi gibi önemli diğer bazı faktörlerin analize alınamamış olmasıdır[26]. Çalışma sonuçlarını topluma genellemeden önce tüm bu kısıtılıklar göz önünde bulundurulmalıdır.

\section{SONUÇ}

AP danışmanlık hizmeti kadınların tercihlerine önemli düzeyde etki etmekte olup uygun yöntemlerin seçimi üzerinde olumlu katkıları bulunmaktadır. Bu hizmetlerin erişilebilir olması ve kadınların akıllarındaki sorulara cevap verebilecek yeterlilikte olması; kadınların kendi kişisel özellik ve sağlık durumlarına uygun kontraseptif yöntem tercihini kolaylaştrabilecektir.

Çıkar çatışması ve finansal destek

Bu çalışmanın hiçbir aşamasında hiçbir kişi, kurum ya da kuruluştan maddi destek alınmamıştır. Ayrıca yazarlar arasında hiçbir çıkar çatışması bulunmamaktadır.

Teşekkür

Ankete katılarak bu çalışmanın yapılmasında emeği bulunan tüm kadınlara teşekkür ederiz.

\section{REFERANSLAR}

1.Sexual rights: an IPPF declaration. Londra, İngiltere: International Planned Parenthood Federation; 2008.

2.Okour AM, Saadeh RA, Zaqoul M. Evaluation of Family Planning Counselling in North Jordan. Sultan Qaboos University medical journal. 2017;17:e436-e43. https://doi.org/10.18295/squmj.2017.17.04.010

3.Mbizvo MT, Phillips SJ. Family planning: choices and challenges for developing countries. Best practice \& research Clinical obstetrics \& gynaecology. 2014;28:931-43. https://doi.org/10.1016/j.bpobgyn.2014.04.014

4.Abbott J, Feldhaus KM, Houry D, Lowenstein SR. Emergency contraception: what do our patients know? Annals of emergency medicine. 2004;43:376-81. https://doi.org/10.1016/S019606440301120X

5.Bellizzi S, Mannava P, Nagai M, Sobel HL. Reasons for discontinuation of contraception among women with a current unintended pregnancy in 36 low and middle-income countries. Contraception. 2020;101:26-33. https://doi.org/10.1016/j.contraception.2019.09.006

6.Koyuncuer A. Kontrasepsiyon ve Türkiye'de Durum. Sürekli Tıp Eğitim Dergisi. 2004;13:455-9

7.2018 Türkiye Nüfus ve Sağlık Araştırması. Ankara, Türkiye: Hacettepe Üniversitesi Nüfus Etütleri Enstitüsü, T.C. Cumhurbaşkanlığı Strateji ve Bütçe Başkanlığı ve TÜBITAK; 2019.

8.Family planning: accelerating the way ahead. The Lancet. 2017;390:2527. https://doi.org/10.1016/S0140-6736(17)33247-6

9.von Elm E, Altman DG, Egger M, Pocock SJ, Gøtzsche PC, Vandenbroucke JP, et al. The Strengthening the Reporting of Observational Studies in Epidemiology (STROBE) Statement: Guidelines for Reporting Observational Studies. 2007;18:800-4. https://doi.org/10.1097/EDE.0b013e3181577654

10.Blumenthal PD, Voedisch A, Gemzell-Danielsson K. Strategies to prevent unintended pregnancy: increasing use of long-acting reversible contraception. Human reproduction update. 2011;17:121-37. https://doi.org/10.1093/humupd/ dmq026

11.Ruddick C. Long-acting reversible contraception: reducing unintended pregnancies. Community practitioner : the journal of the Community Practitioners' \& Health Visitors' Association. 2009;82:24-7
12.Lotke PS. Increasing Use of Long-Acting Reversible Contraception to Decrease Unplanned Pregnancy. Obstetrics and gynecology clinics of North America. 2015;42:557-67. https://doi.org/10.1016/j.ogc.2015.07.008

13.Wulifan JK, Brenner S, Jahn A, De Allegri M. A scoping review on determinants of unmet need for family planning among women of reproductive age in low and middle income countries. BMC women's health. 2016;16:2-. https:// doi.org/10.1186/s12905-015-0281-3

14.Rominski SD, Sk Morhe E, Maya E, Manu A, Dalton VK. Comparing Women's Contraceptive Preferences With Their Choices in 5 Urban Family Planning Clinics in Ghana. Global health, science and practice. 2017;5:65-74. https://doi.org/10.9745/GHSP-D-16-00281

15.Memon A, Hamid S, Kumar R. Client Satisfaction And Decision Making Amongst Females Visiting Family Planning Clinics In Hyderabad, Pakistan. Journal of Ayub Medical College, Abbottabad : JAMC. 2017;29:626-9

16.Chhabra HK, Mohanty IR, Mohanty NC, Thamke P, Deshmukh YA. Impact of Structured Counseling on Choice of Contraceptive Method Among Postpartum Women. Journal of obstetrics and gynaecology of India. 2016;66:471 9. https://doi.org/10.1007/s13224-015-0721-x

17.Egarter C, Frey Tirri B, Bitzer J, Kaminskyy V, Oddens BJ, Prilepskaya $\mathrm{V}$, et al. Women's perceptions and reasons for choosing the pill, patch, or ring in the CHOICE study: a cross-sectional survey of contraceptive method selection after counseling. BMC women's health. 2013;13:9-. https://doi. org/10.1186/1472-6874-13-9

18.Bitzer J, Gemzell-Danielsson K, Roumen F, Marintcheva-Petrova M, van Bakel B, Oddens BJ. The CHOICE study: effect of counselling on the selection of combined hormonal contraceptive methods in 11 countries. The European journal of contraception \& reproductive health care : the official journal of the European Society of Contraception. 2012;17:65-78. https://doi.org/10. 3109/13625187.2011.637586

19.Yeshaya A, Ber A, Seidman DS, Oddens BJ. Influence of structured counseling on women's selection of hormonal contraception in Israel: results of the CHOICE study. International journal of women's health. 2014;6:799-808. https://doi.org/10.2147//JWH.S45397

20.Verran A, Evans S, Lin DJ, Griffiths F. The experiences and perceptions of family planning of female Chinese asylum seekers living in the UK. The journal of family planning and reproductive health care. 2015;41:122-7. https:// doi.org/10.1136/jprhc-2013-100764

21.Nelson AL, Cohen S, Galitsky A, Hathaway M, Kappus D, Kerolous M, et al. Women's perceptions and treatment patterns related to contraception: results of a survey of US women. Contraception. 2018;97:256-73. https://doi.org/10.1016/j. contraception.2017.09.010

22.Madden T, Secura GM, Nease RF, Politi MC, Peipert JF. The role of contraceptive attributes in women's contraceptive decision making. American journal of obstetrics and gynecology. 2015;213:46.e1-.e6. https://doi.org/10.1016/j.ajog.2015.01.051

23.Marshall C, Guendelman S, Mauldon J, Nuru-Jeter A. Young Women's Contraceptive Decision Making: Do Preferences for Contraceptive Attributes Align with Method Choice? Perspectives on sexual and reproductive health. 2016;48:119-27. https://doi.org/10.1363/48e10116

24.Callegari LS, Zhao X, Schwarz EB, Rosenfeld E, Mor MK, Borrero S. Racial/ ethnic differences in contraceptive preferences, beliefs, and self-efficacy among women veterans. American journal of obstetrics and gynecology. 2017;216:504.e1e10. https://doi.org/10.1016/j.ajog.2016.12.178

25.Morse JE, Ramesh S, Jackson A. Reassessing Unintended Pregnancy: Toward a Patient-centered Approach to Family Planning. Obstetrics and gynecology clinics of North America. 2017;44:27-40. https://doi.org/10.1016/j.ogc.2016.10.003 
26.Lundgren R, Cachan J, Jennings V. Engaging men in family planning in four countries. World health \& population. 2012;14:44-51. https://doi. services delivery: experiences introducing the Standard Days Method $₫$ org/10.12927/whp.2013.23097 